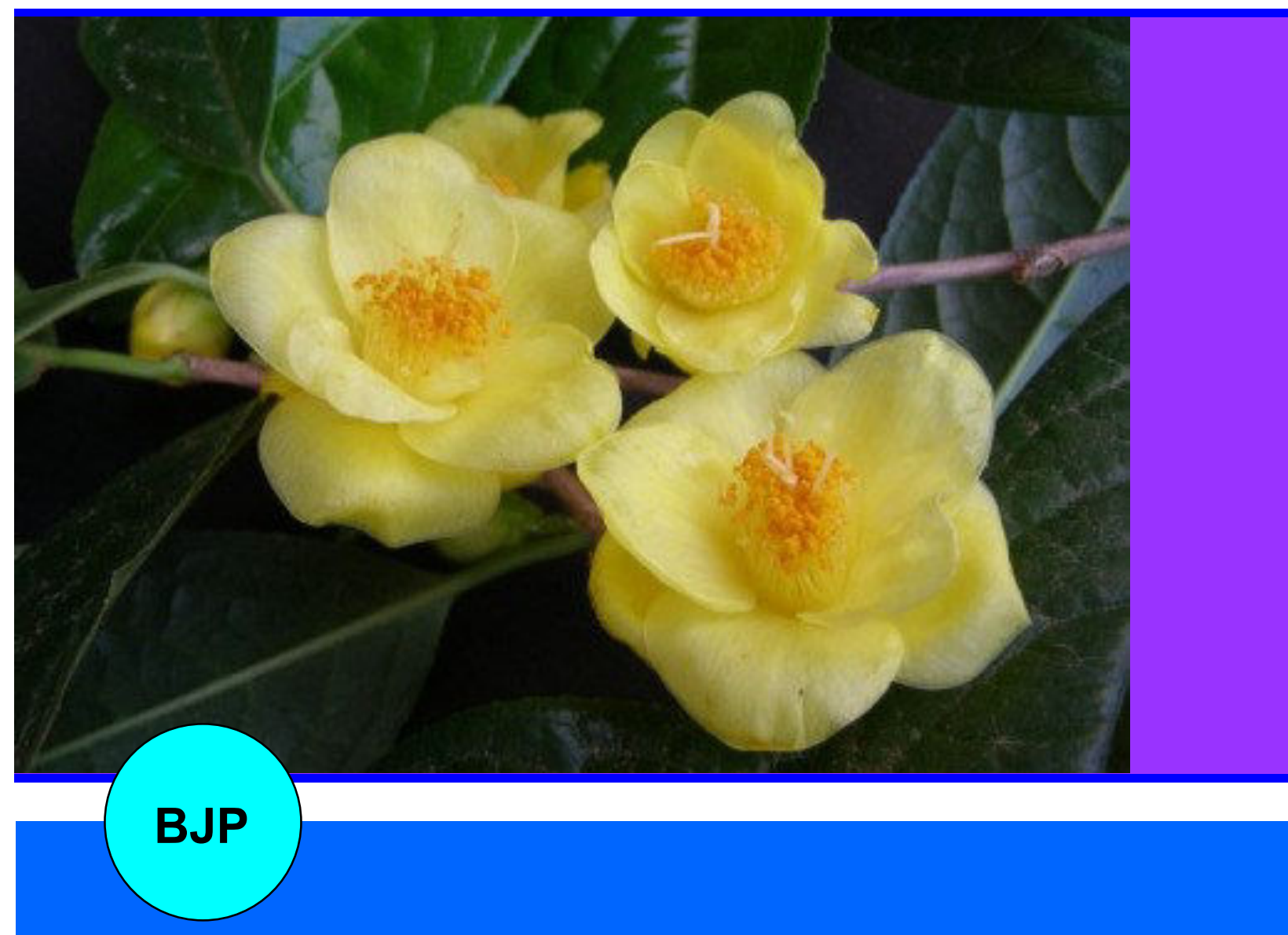

Bangladesh Journal of Pharmacology

Research Article

Hypoglycemic effect of Camellia chrysantha extract on type 2 diabetic mice model 


\title{
Hypoglycemic effect of Camellia chrysantha extract on type 2 diabetic mice model
}

\author{
Lai Wang, Debmalya Roy, Sen Sen Lin, Sheng Tao Yuan and Li Sun
}

Jiangsu Key Laboratory of Drug Screening, China Pharmaceutical University, Nanjing 210009, China.

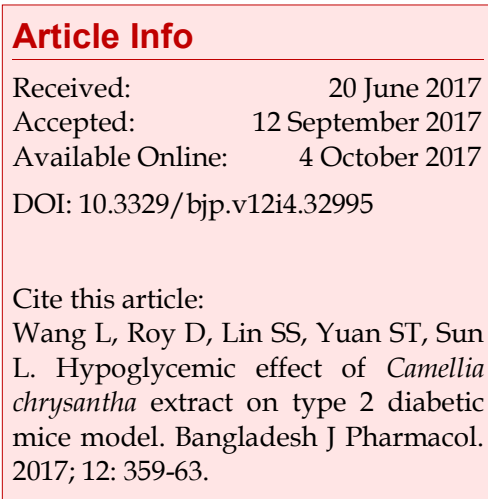

\begin{abstract}
The aim of this study was to investigate the hypoglycemic effect of Camellia chrysantha using type 2 diabetic mice model. The ethyl acetate/ dichloromethane extract exhibited the most effective hypoglycemic effect. Compared to model group, all the three groups of C. chrysantha extracts significantly improved the mice's behavioral performance, weight, reduced water and food intake. The ethyl acetate/dichloromethane extract of C. chrysantha significantly reduced the blood glucose level in the first week after administration and the crude extract also showed a significant effect after longer time administration. All the three extracts reduced the fasting blood glucose level to a certain extent and ethyl acetate/dichloromethane extract exhibited most significant effect among all the three extracts.
\end{abstract}

\section{Introduction}

Diabetes is a metabolic disease caused by an absolute or relative deficiency of insulin secretion. The disease is controlled by insulin or oral hypoglycemic agent. Some plants have blood sugar lowering effect. Recently emphasis is given on traditional medicine (Emeka et al., 2015).

Camellia chrysantha $(\mathrm{Hu})$ tuyama is a traditional medicine of the Zhuang nationality in Guangxi province. It has been mentioned in Li Shizhen's Compendium of Materia Medica: C. chrysantha native to the South, bloom in winter with red or yellow petal and yellow stamen. Cooked tender leaves of C. chrysantha is edible and the dried leaf can be used as traditional Chinese medicine decoction pieces (Jiang, 2005; Wang and Wu, 1932).

There are pharmacological records in the compendium of folk medicine in Guangxi, the record of Chinese Materia, Medica of the dictionary of Chinese, Materia Medica standards and the medicinal plants of Guangxi (Srivastava et al., 1996; Zhao et al., 2010). Furthermore, it is also used in the treatment of sore throat, nephritis, hepatitis, dysentery, diarrhea, hypertension, urinary tract infections and irregular menstruation. It has been revealed through chemical and pharmacological studies on $C$. chrysantha that a variety of natural active ingredients are present including flavonoids, polysaccharides, polyphenols and ginsenoside which are responsible for the anti-cancer (Chen et al., 2009; Lin et al., 2013; Roy et al., 2017), anti-oxidant (En-chuang et al., 2010; Qin et al., 2008), antihyperlipidemic (Liu et al., 2012; Rao and Wei, 2012), anti-allergic (Wei et al., 2015), anti-light aging (Qin et al., 2008) and bacteriostatic activity (Zou et al., 2012) in vitro and in vivo. However, this is for the first time we have reported that $C$. chrysantha also has an anti-diabetic effect.

\section{Materials and Methods}

\section{Experimental animal}

In the phase I experiment, C57BL/6J male mice weighing $14 \pm 2 \mathrm{~g}$ were used. They were purchased from 
Nanjing Qing Long Shan animal breeding grounds (Certificate No.: 201607466). In the dose-effect relationship experiment, C57BL/6J male mice (weight $20 \pm 2 \mathrm{~g}$ ) were used and were purchased from the Shanghai Sippr-BK Laboratory Animal Co. Ltd. (Certificate No.: SCXK 201230016).

\section{Experimental drugs and reagents}

Ethyl acetate/dichloromethane, $n$-butyl alcohol and crude extract of C. chrysantha were given by Prof. Jia Aiqun of Nanjing University of Science and Technology. Metformin hydrochloride was purchased from the Dalian Mellon Biological Technology Co., Ltd (batch number: A0830A). Glucose detection kits were purchased from the Nanjing Whitman Biological Technology Co., Ltd. Streptozotocin was purchased from the Sigma Company (USA; batch number: B74723). Highfat diet was purchased from the Nanjing Qing Long Shan animal breeding grounds.

\section{Preparations of drugs and reagents}

The concentration of C. chrysantha extract was $10 \mathrm{mg} /$ $\mathrm{mL}$ prepared using $0.5 \%$ sodium carboxymethyl cellulose solution. The concentration of metformin hydrochloride was $25 \mathrm{mg} / \mathrm{mL}$ prepared using normal saline solution. The concentration of streptozotocin was 8.5 $\mathrm{mg} / \mathrm{mL}$ prepared using $0.1 \mathrm{~mol} / \mathrm{L}$ citrate buffer with $\mathrm{pH} 4.2$.

\section{Model establishment and administration}

C57BL/6J mice were taken randomly as control group after adaptive food for 1 week and were fed with basal food all the time. The rest of the mice were fed with high-fat food for 4 weeks, then were fasted for 15 hours. During fasting no food was given but only water had been given. Streptozotocin $(85 \mathrm{mg} / \mathrm{kg})$ had been administered intraperitoneally. Food had been given after 4 hours of the injection. Further, streptozotocin had been administered 5 days later, by the same process. After 3 days, blood samples were collected via fundus after venous plexus. The serum was separated for the determination of blood glucose concentration using TECAN safire2 full wavelength multi-functional microplate reader (TECAN Corporation, Switzerland). Thereafter, picked out mice whose blood glucose concentration within 11.1-20 mmol/L as type 2 diabetic mice.

The diabetic mice were randomly divided into 5 groups viz. model, positive control, ethyl acetate/dichloromethane extract of $C$. chrysantha, $n$-butyl alcohol extract of C. chrysantha and crude extract of C. chrysantha. Each group contained 8 mice except the model group, which contained 9 mice. Diabetic mice were fed with high-fat feed. Positive control group mice were given $250 \mathrm{mg} /$ $\mathrm{kg}$ metformin hydrochloride with the intragastric administration. Metformin hydrochloride solution was prepared before use. Extracts of C. chrysantha groups were given corresponding extract of C. chrysantha $0.5 \%$ sodium carboxymethyl cellulose solution with the dose of $100 \mathrm{mg} / \mathrm{kg}$ in the way of intragastric administration. Once a day and up to 5 weeks. Control and model group were given corresponding volume $0.5 \%$ sodium carboxymethyl cellulose solution. In dose-effect relationship experiment of ethyl acetate/ dichloromethane extract of C. chrysantha, the method of model establishment was same with preliminary screening experiment. Diabetic mice were divided to 5 groups: model, positive control, high dose $(200 \mathrm{mg} / \mathrm{kg})$, medium dose (100 mg/ $\mathrm{kg}$ ) and low dose (50 mg/kg). Each group had 10 mice and the drug had been administered up to 5 weeks.

\section{Observation of body signs}

The hair color, mental status, behavioral performance, and food and water intake were observed.

\section{Weight}

The body weight of each mouse on every 7 days was recorded and computed the difference of body weight of each group.

\section{Water intake and urine volume}

Observed left water volume in water bottle of every group and degree of wet of woodchips bed which reflected urine volume to a certain extent.

\section{Fasting blood glucose concentration}

In the 1st and 4th week in phase I experiment and 4th and 5 th week in the dose-effect relationship experiment of ethyl acetate/dichloromethane extract, mice were fasted 12 hours and could not help but water, then blood sample were collected via fundus after venous plexus, separated serum in time for measuring blood glucose concentration using glucose kit.

\section{Oral glucose tolerance test}

In the fifth week after administration in preliminary screening experiment, mice were fasted for 12 hours and given only water but no food, then blood samples were collected via fundus after venous plexus, measured blood glucose concentration as 0 hour blood glucose value labeled with BG 0 . After collecting blood samples of 0 hour administrated corresponding drugs immediately followed by injection of glucose solution with the dose of $2 \mathrm{~g} / \mathrm{kg}$. Blood samples of $30 \mathrm{~min}, 1$ hour and 2 hours were collected via fundus after venous plexus for measuring blood glucose which were labeled with BG 0.5, BG 1 and BG 2. Calculated area under blood glucose-time curve of every group.

Calculation formula: AUC $=($ BG $0+0.5) \times 0.25+($ BG 0.5 $+1) \times 0.25+($ BG $1+2) \times 0.5$.

\section{Statistical analysis}

The statistical differences of different groups compared to control group were analyzed by two-way ANOVA. 
The $p<0.05$ considered statistically significant.

\section{Results}

\section{Behavioral performance}

Normal mice were flexible and active black and glossy hair, they were taking normal diet. But after administration of STZ, mice appeared gloomy hair, behavioral change and turned into a polydipsia, polyphagia, and polyuria. All 3 extracts of $C$. chrysantha alleviated behavioral performance and increased activities of mice. Ethyl acetate/dichloromethane extract of $C$. chrysantha is most effective among all of these 3 extracts.

\section{Body weight}

The body weight of mice decreased from $4^{\text {th }}$ week because of administering streptozotocin which destroyed the pancreatic $\beta$-cells selectively which elicited diabetes. Body weight was decreased mostly after one week of twice administration of streptozotocin and stopped decreasing with long-time administration of drugs, especially positive control group. In the $C$. chrysantha group, the body weight also increased some what compared to the model group, but not significantly. It indicates extracts of $C$. chrysantha had no significant effect on the mice growth.

\section{Water intake, food intake and urine volume}

After an establishment of successful model water and, food intake and urine volume gradually increased mice of diabetic groups compared to the normal group. After the administration of extracts of C. chrysantha, water intake, food intake and urine volume were decreased in C. chrysantha compared to the model group. Especially ethyl acetate/dichloromethane and crude extract were more effective.

\section{Table I}

Effect on different extracts of $C$. chrysantha on fasting blood-glucose

\begin{tabular}{|c|c|c|c|}
\hline \multirow[t]{2}{*}{ Group } & \multicolumn{3}{|c|}{ Blood glucose level (mmol/L) } \\
\hline & 0 & $1^{\text {st }}$ week & $4^{\text {th }}$ week \\
\hline Control & $3.8 \pm 0.9$ & $3.9 \pm 0.8^{b}$ & $3.5 \pm 0.7 \mathrm{~b}$ \\
\hline Diabetic model & $13.7 \pm 3.4$ & $18.5 \pm 3.9$ & $10.4 \pm 2.5$ \\
\hline $\begin{array}{l}\text { Metformin }(250 \\
\mathrm{mg} / \mathrm{kg})\end{array}$ & $13.8 \pm 2.2$ & $8.8 \pm 3.8^{\mathrm{a}}$ & $5.4 \pm 1.0^{a}$ \\
\hline $\begin{array}{l}\text { Acetate/ } \\
\text { dichloromethane } \\
(100 \mathrm{mg} / \mathrm{kg})\end{array}$ & $13.2 \pm 1.9$ & $8.4 \pm 2.7^{a}$ & $5.1 \pm 2.1^{\mathrm{a}}$ \\
\hline $\begin{array}{l}\text { Crude extract (100 } \\
\mathrm{mg} / \mathrm{kg})\end{array}$ & $14.2 \pm 2.8$ & $11.3 \pm 4.2^{\mathrm{a}}$ & $5.6 \pm 1.3^{a}$ \\
\hline $\begin{array}{l}n \text {-Butyl alcohol } \\
\text { extract }(100 \mathrm{mg} / \mathrm{kg})\end{array}$ & $13.2 \pm 3.0$ & $16.0 \pm 4.0$ & $7.0 \pm 2.0^{a}$ \\
\hline
\end{tabular}

\section{Fasting blood glucose}

The fasting blood glucose level of ethyl acetate/ dichloromethane extract exhibited a significant decrease of glucose level compared to the model group in the $1^{\text {st }}$ week after administration (Table I). This indicated that ethyl acetate/dichloromethane extract of C. chrysantha has a potent hypoglycemic effect. In the $4^{\text {th }}$ week after administration, all 3 extracts of $C$. chrysantha groups exerted reducing fasting blood glucose level compared to the model group.

\section{Oral glucose tolerance test}

Blood glucose concentration at every time point of the model group after administration of glucose solution were significantly higher than normal group (Figure 1). After 5 weeks administration of different extracts of $C$. chrysantha, blood glucose concentration of every time point of 3 extracts of $C$. chrysantha groups were not significantly decreased compared to the model group. This indicates extracts of C. chrysantha does not have a significant effect on OGTT of diabetic mice.

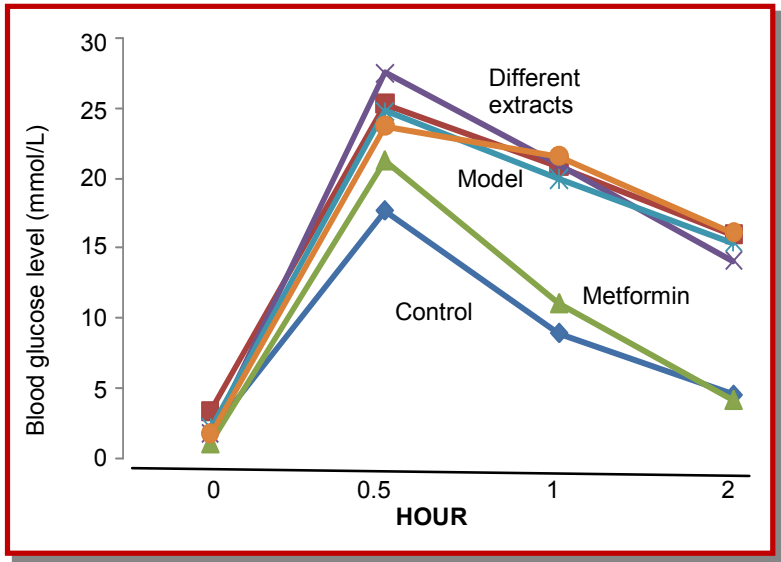

Figure 1: Effects of different concentration of ethyl acetate extract of $C$. chrysantha on oral glucose tolerance test. Cross sign: acetate/dichloromethane $(100 \mathrm{mg} / \mathrm{kg}) ;$ star sign: crude extract $(100 \mathrm{mg} / \mathrm{kg})$; closed circle: $n$-butyl alcohol extract $(100$ $\mathrm{mg} / \mathrm{kg}$ ); closed square: model diabetic; triangular: metformin $250 \mathrm{mg} / \mathrm{kg}$; closed diamond: control

\section{Dose-effect relationship study of ethyl acetate/dichlo- romethane extract}

The dose-effect relationship of ethyl acetate/dichloromethane extract is shown in Table II. All the 3 groups exhibited strong hypoglycemic effect after 4 weeks administration but had no significant difference between the 3 groups, when the dose was between 50-200 $\mathrm{mg} / \mathrm{kg}$. Furthermore, we also performed OGTT experiment to ensure that ethyl acetate/dichloromethane extract of C. chrysantha had no effect on OGTT of diabetic mice (Figure 2). The results showed that 3 doses of ethyl acetate/dichloromethane extract of $C$. chrysantha had no effect on OGTT of diabetic mice. 
Table II

\begin{tabular}{|c|c|c|c|}
\hline \multicolumn{4}{|c|}{$\begin{array}{l}\text { Effect on ethyl acetate/dichloromethane extract of } \\
\text { C. chrysantha on fasting blood-glucose level }\end{array}$} \\
\hline \multirow[t]{2}{*}{ Group } & \multicolumn{3}{|c|}{ Blood glucose level (mmol/L) } \\
\hline & 0 & $4^{\text {th }}$ week & $5^{\text {th }}$ week \\
\hline Control & $2.6 \pm 0.6^{b}$ & $2.5 \pm 0.71^{b}$ & $1.6 \pm 0.57 \mathrm{~b}$ \\
\hline Diabetic model & $17.2 \pm 4.6$ & $15.9 \pm 5.7$ & $10.5 \pm 3.5$ \\
\hline $\begin{array}{l}\text { Metformin (250 } \\
\mathrm{mg} / \mathrm{kg})\end{array}$ & $17.6 \pm 4.3$ & $8.6 \pm 3.5^{b}$ & $5.1 \pm 3.1^{\mathrm{b}}$ \\
\hline \multicolumn{4}{|l|}{ C. chrysantha } \\
\hline $200 \mathrm{mg} / \mathrm{kg}$ & $17.7 \pm 5.4$ & $11.8 \pm 5.7$ & $6.7 \pm 4.1^{\mathrm{a}}$ \\
\hline $100 \mathrm{mg} / \mathrm{kg}$ & $17.3 \pm 4.3$ & $10.2 \pm 2.0^{\mathrm{b}}$ & $6.3 \pm 2.0^{b}$ \\
\hline $50 \mathrm{mg} / \mathrm{kg}$ & $17.3 \pm 4.1$ & $9.4 \pm 2.6^{b}$ & $6.2 \pm 4.3^{a}$ \\
\hline
\end{tabular}

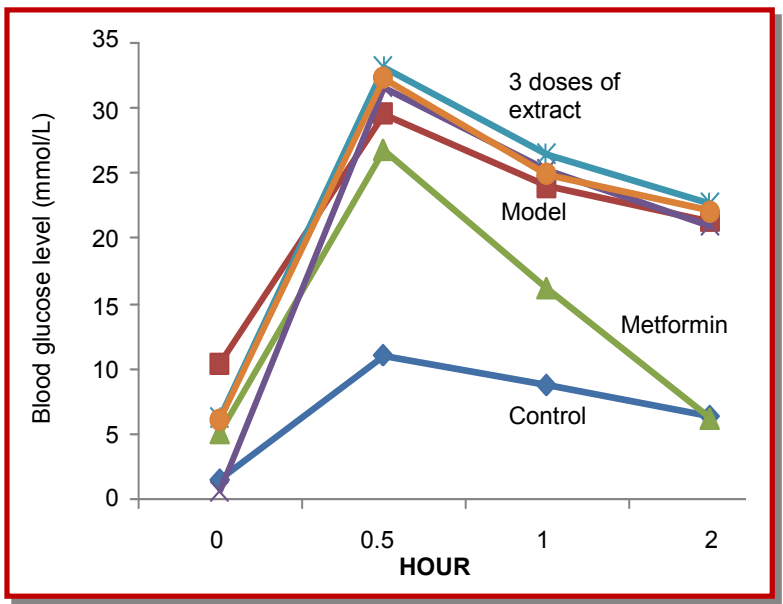

Figure 2: Effects of different concentration of ethyl acetate extract of $C$. chrysantha on oral glucose tolerance test. Cross sign: $200 \mathrm{mg} / \mathrm{kg}$; star sign: $100 \mathrm{mg} / \mathrm{kg}$; closed circle: $50 \mathrm{mg} / \mathrm{kg}$; closed square: model diabetic; triangular: metformin $250 \mathrm{mg} /$ $\mathrm{kg}$; closed diamond: control

\section{Discussion}

C. chrysantha contains polysaccharides, polyphenols, flavonoids and other bioactive components. It also contains abundant natural organic selenium, germanium and manganese (Mukhopadhyay et al., 2016) which seems to be the cause of regulating the blood glucose level. Our work evaluated the hypoglycemic effect of ethyl acetate/dichloromethane, $n$-butyl alcohol and crude extract of C. chrysantha.

In this study, streptozotocin and high-fat diet were used to induce diabetes in mice and evaluated the hypoglycemic effect of C. chrysantha. The dose-effect relationship was studied. We observed that all the 3 extracts of C. chrysantha showed acertain extent of hypoglycemic effect after 4 weeks administration of respective extract of C. chrysantha but ethyl acetate/ dichloromethane extract of $C$. chrysantha exhibited to decrease fasting blood glucose level after 1 week of administration.
This indicated that ethyl acetate/dichloromethane extract has a better hypoglycemic effect compared to other 2 extracts of $C$. chrysantha. But 3 extracts of $C$. chrysantha showed almost exactly the similar effect on oral glucose tolerance test of diabetic mice but the effect was not so potent. The study of dose-effect experiment of ethyl acetate/dichloromethane extract showed that all the 3 doses of ethyl acetate/dichloromethane extract of $C$. chrysantha significantly decreased the fasting glucose concentration but had no effects on OGTT.

Fasting blood glucose level of diabetic mice in preliminary screening experiment was lower than the dose-effect relationship experiment, because of physical differences of two batches of mice that they had different sensitivity to streptozotocin.

\section{Conclusion}

The hypoglycemic effects of three different extracts of C. chrysantha were evaluated and found that the ethyl acetate/dichloromethane extract was the most effective hypoglycemic but had no effect on oral glucose tolerance test of the diabetic mice.

\section{Ethical Issue}

Animal protocols were approved by the Clinical Pharmacy College and Preclinical Medicine, Nanjing, China and rules and regulations were followed during processing of entire experiments on all mice.

\section{Conflict of Interest}

All authors have completed the ICMJE uniform disclosure form and declare no support from any organization for the submitted work.

\section{Acknowledgement}

DR is the recipient of the China Government ScholarshipUniversity Program (China Scholarship Council) for foreign students.

\section{References}

Chen XW, Wei YY, Zhou WP, Pan MJ, Li JS, Shipin K. Study on separation and the anti-microbial effects of the total flavanoids of Emilia sonchifolia. Food Sci Technol. 2009; 1: 163 -65 .

Emeka E, Oluwatoyin A, Adekunle O, Ignis I. Preliminary phytochemical screening and evaluation of hypoglycemic properties of the root extract of Uveria chamae. Bangladesh J Pharmacol. 2015; 10: 326-31.

En-chuang N, Lu W, Xiao-ming Q, Yuan-zhen Z. Study on the 
anti-oixidation activity of polyphenols from Camellia chrysantha (Hu)[J]. Food Sci Technol. 2010; 8: 25.

Jiang WY. Therapeutic wisdom in traditional Chinese medicine: A perspective from modern science. Trends Pharmacol Sci. 2005; 26: 558-63.

Lin JN, Lin HY, Yang NS, Li YH, Lee MR, Chuang CH, Ho CT, Kuo SC, Way TD. Chemical constituents and anti-cancer activity of yellow camellias against MDA-MB-231 human breast cancer cells. J Agric food Chem. 2013; 61: 9638-44.

Liu N, Zhu PP, Li JL. Research progress in extraction of flavonoids. The Beverage Industry. 2012; 7: 11

Mukhopadhyay M, Mondal TK, Chand PK. Biotechnological advances in tea (Camellia sinensis [L.] O. Kuntze): A review. Plant Cell Rep. 2016; 35: 255-87.

Qin XM, Lin HJ, Ning EC, Wei L. Anti-oxidative properties of extracts from the leave of Camellia chrysantha $(\mathrm{Hu})$ Tuyama [J]. Food Sci Technol. 2008; 2: 24-27.

Rao QL, Wei GN. Experimental study on the effect of yinge jiannao tea on hemorheology [J]. Yunnan J Tradit Chin Med Materia Medica. 2012; 5: 35.
Roy D, Sheng GY, Herve S, Carvalho E, Mahanty A, Yuan S, Sun L. Interplay between cancer cell cycle and metabolism: Challenges, targets and therapeutic opportunities. Biomed Pharmacother. 2017; 89: 288-96.

Srivastava J, Lambert J, Vietmeyer N. Medicinal plants: An expanding role in development. World Bank Publications. 1996.

Wang J, Wu L. History of Chinese medicine. World Scientific. 1932

Wei JB, Li X, Song H, Liang YH, Pan YZ, Ruan JX, Qin X, Chen YX, Nong CL, Su ZH. Characterization and determination of anti-oxidant components in the leaves of Camellia chrysantha $\mathrm{Hu}$ ) Tuyama based on composition-activity relationship approach. J Food Drug Anal. 2015; 23: 40-48.

Zhao Z, Liang Z, Chan K, Lu G, Lee ELM, Chen H, Li L. A unique issue in the standardization of Chinese Materia Medica: Processing. Planta Medica. 2010; 76: 1975-86.

Zou DF, Qiu YT, Xie AZ, Ye M, Wang FF. GC-MS analysis of ether extraction of Camellia chrysantha. Chin J Exp Tradit Med Formulae. 2012; 20: 42.

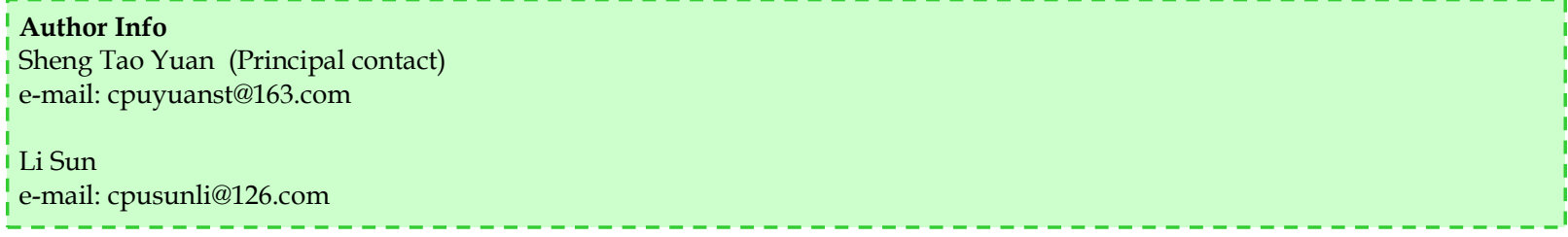

